\title{
A DIMENSÃO JURÍDICO-POLÍTICA DA SUSTENTABILIDADE E O DIREITO FUNDAMENTAL À RAZOÁVEL DURAÇÃO DO PROCEDIMENTO ${ }^{1}$
}

\author{
SUSTAINABILITY OF LEGAL AND POLITICAL DIMENSION AND \\ FUNDAMENTAL RIGHT TO REASONABLE PROCEDURE \\ DURATION \\ Magno Federici Gomes ${ }^{2}$ \\ Leandro José Ferreira ${ }^{3}$
}

Recebido em: 14/01/2017 Aceito em: 29/10/2017

federici@pucminas.br leandrojfadv@gmail.com
Resumo: O presente estudo tem como objetivo trabalhar a dimensão jurídico-política da sustentabilidade, que aponta para uma proposta de razoável duração do procedimento judicial como meta indispensável para se alcançar a plenitude do ideal de sustentabilidade. Será abordado o direito fundamental da razoável duração do procedimento, insculpido na Constituição da República de 1988 (CR/1988). Para tanto, foram utilizados na realização desta pesquisa, o método jurídico-teórico e o raciocínio dedutivo, com técnica de pesquisa bibliográfica. Ao final do trabalho, pode-se evidenciar que os direitos fundamentais, em especial a razoável duração do procedimento, devem ser devidamente desenvolvidos e efetivados pelo Estado Democrático de Direito, de modo a objetivar e consubstanciar um pleno desenvolvimento pautado na sustentabilidade, com vistas a propiciar o bem-estar duradouro para as presentes e futuras gerações.

Palavras-chave: Sustentabilidade. Dimensão jurídico-política. Direitos Fundamentais. Razoável duração do procedimento.

\begin{abstract}
This study aims to work the scale legal and political sustainability, which points to a proposal for a reasonable duration of the judicial procedure as an essential goal to reach the fullness of the ideal of sustainability. Will address the fundamental of reasonable duration of the procedure, in the Brazilian Constitution of 1988 (CR/1988). Therefore, were used in this research the legal and theoretical method and deductive reasoning, with a bibliographical research technique. At the end of the survey, one can show that the fundamental rights, in particular the reasonable duration of the procedure, must be properly developed and made effective by the democratic rule of law in order to objectify and substantiate full development guided by the sustainability, in order to provide lasting well-being for present and future generations.
\end{abstract}

Keywords: Sustainability. Legal-political dimension. Fundamental rights. Reasonable duration of the judicial procedure.

\section{INTRODUÇÃO}

O estudo da dimensão jurídico-política da sustentabilidade, como principal objeto dessa pesquisa, será trabalhada conforme os conceitos e ditames apresentados por Freitas (2016).

Nesse aspecto, a dimensão jurídico-política da sustentabilidade evidencia-se de modo a permitir uma maior e melhor aplicação desses conceitos na prática cotidiana, com o objetivo de resguardar e desenvolver os direitos fundamentais à longevidade digna, à alimentação adequada, ao

\footnotetext{
${ }^{1}$ Trabalho financiado pelo Edital no 05/2016 (Projeto no FIP 2016/11173-S2) do FIP/PUC, resultante dos Grupos de Pesquisas (CNPQ): Regulação Ambiental da Atividade Econômica Sustentável (REGA) e CEDIS (FCT-PT).

2 Escola Superior Dom Helder Câmara, PUC Minas e Faculdade de Direito Arnaldo Janssen.

${ }^{3}$ PUC Minas e Escola Superior Dom Helder Câmara
} 
ambiente ecologicamente equilibrado, à educação de qualidade, a uma democracia plena sem vícios, à informação livre e de qualidade, ao processo judicial e administrativo de razoável duração, à segurança, à renda digna oriunda do trabalho, à boa administração pública e à moradia digna (FREITAS, 2016, p. 74-75).

Nesse viés, será necessária uma incursão ao direito fundamental à efetividade do processo. A aplicação desse direito 4 relaciona-se diretamente com os pilares da sustentabilidade, ao passo que o pleno desenvolvimento da sustentabilidade depende de um esforço conjunto em prol da aplicação e desenvolvimento dos direitos fundamentais, de modo a possibilitar o bem-estar das presentes e futuras gerações, conforme acentua Freitas (2016).

Por isso, uma ligação entre a sustentabilidade e a razoável duração do procedimento se mostra como principal objeto de estudo, ao passo que a sociedade anseia pela entrega de uma tutela jurisdicional em tempo adequado a produzir seus efeitos e gerar bem-estar intergeracional.

Para tanto, foram utilizados na realização deste artigo o método jurídico-teórico e raciocínio dedutivo, com técnica de pesquisa bibliográfica. A pesquisa se justifica na medida em que a comunidade acadêmica anseia por um melhor delineamento dos conceitos da sustentabilidade, sobretudo o conceito relacionado à sua dimensão jurídico-política.

Ao final, um discurso conexo entre o direito fundamental da razoável duração do procedimento e o caminho para a sustentabilidade se fez necessário.

\section{A DIMENSÃO JURÍDICO-POLÍTICA DA SUSTENTABILIDADE}

As considerações para esse capítulo estão voltadas a conjugar e apresentar as dimensões da sustentabilidade, em especial a dimensão jurídico-política desse novo paradigma denominado sustentabilidade. A sustentabilidade denota uma preocupação internacional em promover o pleno desenvolvimento sustentável dos povos e das comunidades de modo a preservar o meio ambiente equilibrado para as presentes e futuras gerações.

Alinha-se a esse novo paradigma de desenvolvimento a sustentabilidade, que surge como meta a ser conquistada, de modo que as preocupações com o desenvolvimento sustentável vão muito além de proteger e preservar o meio ambiente (o que não é tarefa simples de ser cumprida). Trata-se de um esforço que envolve várias nuances do ideal de desenvolvimento e, por isso, Freitas (2016) retrata que a: "sustentabilidade é multidimensional, porque o bem-estar é multidimensional" (FREITAS, 2016, p. 61).

Ao encontro desse entendimento, Sachs (2009) evidencia que:

Ao mesmo tempo, pode valer a pena colocar juntas as duas idéias-força mencionadas [...], reconceitualizando-se o desenvolvimento como apropriação efetiva de todos os direitos humanos, políticos, sociais, econômicos e culturais, incluindo-se aí o direito coletivo ao meio ambiente (SACHS, 2009, p. 60).

\footnotetext{
${ }^{4}$ Por alguns entendido como princípio constitucional do processo.
} 
Nesse entendimento as dimensões da sustentabilidade devem ser desenvolvidas de modo conjunto, onde nenhuma pode ser deixada de lado ou esquecida com o passar do tempo, pois a exemplo, a preservação ambiental, que está dentro do conceito da dimensão ambiental da sustentabilidade, se não corretamente desenvolvida pode levar ao colapso a dimensão social, e o contrário também poderá ocorrer, pois, "a deterioração material do planeta é insustentável, mas a pobreza também é insustentável, a exclusão social também é insustentável, assim como a injustiça, a opressão, a escravidão e a dominação cultural e econômica" (MAFRA, 2015, p. 555).

Froehlich (2014), nesse sentido, pontua: "é consensual que deve haver inter-relações entre as dimensões e que indicadores que ficam restritos a apenas uma dimensão não refletem a sustentabilidade" (FROEHLICH, 2014, p. 165) 5 .

Portanto, há que ser evidenciado que as falácias e as falsas promessas de desenvolvimento sustentável precisam ser superadas com o fito de possibilitar a aplicação dos ditames das dimensões da sustentabilidade, de maneira conexa e concreta a produzir seus efeitos nas cinco dimensões propostas por Freitas (2016). Nesse ponto, Freitas (2016) desenvolve o conceito de sustentabilidade:

Trata-se do princípio constitucional que determina, com eficácia direta e imediata, a responsabilidade do Estado e da sociedade pela concretização solidária do desenvolvimento material e imaterial, socialmente inclusivo, durável e equânime, ambientalmente limpo, inovador, ético e eficiente, no intuito de assegurar, preferencialmente de modo preventivo e precavido, no presente e no futuro, o direito ao bem-estar (FREITAS, 2016, p. 43).

Apresentado o conceito de sustentabilidade e demonstrado que em sua inteireza ela é multidimensional, pois agrupa as dimensões social, ambiental, econômica, ética e jurídico-política, torna-se indispensável complementar cada uma de suas dimensões e suas próprias especificidades, pois "a sustentabilidade pode ser analisada e caracterizada a partir de diferentes dimensões" (FROEHLICH, 2014, p. 157).

A dimensão social da sustentabilidade enfatiza uma necessária e indispensável preocupação com o ser humano e sua qualidade de bem-estar, pois existe uma íntima relação entre a qualidade de vida do ser humano e a qualidade do meio ambiente, uma vez que são conceitos indissociáveis.

Na dimensão econômica da sustentabilidade verifica-se que no conceito de desenvolvimento sustentável o prisma do fator econômico jamais pode ser tratado com indiferença ou ser deixado de lado, pois é a partir de uma economia saudável e responsável, que será possível a geração de igualdades sociais, com o pleno desenvolvimento sustentável nos padrões da sustentabilidade.

A dimensão ética da sustentabilidade está diretamente voltada para a relação da justiça intergeracional, de modo que a coletividade da presente geração é responsável pela herança ambiental e social que serão passadas para as gerações futuras, num plexo de solidariedade e fraternidade de aceitação do ser humano enquanto pessoa e do meio ambiente enquanto natureza, responsável por gerir a vida de todos os seres vivos.

No aspecto da dimensão ambiental da sustentabilidade, é inegociável a premissa de que o meio ambiente equilibrado à sadia qualidade de vida para as presentes e futuras gerações, deve ser devidamente preservado e protegido, sob pena de a natureza não suportar mais a vida humana na Terra.

\footnotetext{
${ }^{5}$ No mesmo sentido e analisando um caso concreto, BIZAWU; GOMES, 2016, p. 18-21.
} 
Medidas precisam ser tomadas muito além de conferências internacionais e cartas de boas intenções. Medidas sérias e imediatas de combate à poluição da água, do solo, do ar e da terra precisam ser amplamente difundidas e implementadas. As falácias e os discursos dotados de belas e representativas palavras precisam ser sistematicamente permutados para ações concretas e eficientes de combate ao desmatamento e ao incessante desejo de poluir o planeta.

Nesse compasso de desenvolvimento pautado na sustentabilidade, é de se observar que neste estudo foram apontadas, até o momento, quatro diferentes dimensões da sustentabilidade, mas que se entrelaçam entre si, com o fito de modificar o atual cenário de degradação ambiental financiado pelo modelo capitalista de crescimento econômico. No entanto, uma quinta dimensão da sustentabilidade é evidenciada no presente estudo a partir de Freitas (2016), que assevera:

Dimensão jurídico-política ecoa o sentido de que a sustentabilidade determina, com eficácia direta e imediata, independentemente de regulamentação, a tutela jurídica do direito ao futuro e, assim, apresenta-se como dever constitucional de proteger a liberdade de cada cidadão (titular de cidadania ambiental ou ecológica), nesse status, no processo de estipulação intersubjetiva do conteúdo intertemporal dos direitos e deveres fundamentais das gerações presentes e futuras, sempre que viável diretamente (FREITAS, 2016, p. 72).

Essa dimensão, conforme conceito proposto, apresenta-se como uma junção de fatores capazes de possibilitar o pleno desenvolvimento sustentável gerador de bem-estar para as presentes e futuras gerações. Aqui, evidencia-se uma união basilar entre as dimensões social, econômica, ética e ambiental na formação da dimensão jurídico-política.

A dimensão jurídico-política visa a efetivar e desenvolver os direitos fundamentais das presentes e futuras gerações, com o objetivo de asseverar e reforçar o plexo de desenvolvimento consubstanciado na preservação e proteção ambiental, sem, contudo, perder de vista a promoção social, o respeito à dignidade humana e aos direitos humanos, a melhor e adequada distribuição da renda e os conceitos de origem ética, que são vertentes indissociáveis do conceito de sustentabilidade.

Trata de uma determinação principiológica vinculante que visa ao aperfeiçoamento da tutela efetiva dos direitos fundamentais para que possam se materializar em bem-estar para as presentes e futuras gerações, num prisma de proteção da vida em suas diferentes formas.

Desse modo evidencia-se na dimensão jurídico-política um novo modelo de desenvolvimento pautado também na previsibilidade, de modo a consubstanciar os princípios da precaução e da prevenção, evitando danos irreparáveis para as presentes e futuras gerações. Freitas (2016) propõe: "supões redesenhar o direito administrativo da regulação, que não mais sucumba à omissão causadora de danos inter e intrageracionais, sob a alegação de risco de captura" (FREITAS, 2016, p. 73).

Essa dimensão da sustentabilidade propõe o pleno desenvolvimento do Estado Democrático de Direito com vistas a atender o mínimo necessário e garantido constitucionalmente para possibilitar a vida em todas as suas formas, sem que para tanto ocorra degradação ambiental.

É, de fato, um esforço conjunto no sentido de que a humanidade possa prosperar de forma unida com o planeta, onde os limites e as condições de cada um sejam devidamente respeitados, cumpridos e fiscalizados pelo Estado Democrático de Direito, engajado no modo de vida pleno e 
digno, "consoante, se a sustentabilidade em si é um novo paradigma e/ou um fenômeno, do ponto de vista jurídico ela é um requisito" (CRUZ; GLASENAPP, 2014, p. 380). **

Nesse aspecto, a dimensão jurídico-política da sustentabilidade visa a resguardar os direitos fundamentais concernentes à longevidade digna; o direito à alimentação adequada; o direito ao meio ambiente limpo; o direito à boa educação e de qualidade; o direito à democracia; o direito à informação imparcial; o direito à razoável duração do procedimento; o direito à segurança; o direito à renda oriunda do trabalho; o direito à boa administração pública e o direito à moradia (FREITAS, 2016, p. 74-75).

Nessa órbita, é possível evidenciar que essa dimensão propõe um pleno desenvolvimento das dimensões já apontadas anteriormente, no objetivo de estabelecer um liame conjectural de sustentabilidade que foque o todo na esfera do desenvolvimento sustentável.

A seguir, o que se propõe é o estudo de cada um dos direitos fundamentais formadores e norteadores da dimensão jurídico-política da sustentabilidade, conforme passará a averiguar.

\subsection{Direito à longevidade digna}

O direito à longevidade digna está diretamente alicerçado na idéia de viver com dignidade e envelhecer com respeito, onde os direitos à saúde digna possam ser rapidamente acessados sem as incriveis burocracias cotidianas. Vai além de um simples viver ou passar pela vida, pressupõe um ciclo de vida útil e proveitoso mediante o acesso às garantias constitucionais da dignidade da pessoa humana.

Nessa ótica, para se alcançar o pleno desenvolvimento pautado na sustentabilidade é imprescindível que o direito à dignidade da pessoa humana seja respeitado em todas as relações cotidianas, desde as mais simples às mais complexas.

Evidencia-se, no cenário nacional, um grande afastamento das políticas públicas no que diz respeito aos direitos básicos que são postos à disposição do cidadão, sobretudo ao idoso que precisa de medicamentos mais acessíveis e cuidados médicos corriqueiros. Esse e qualquer outro padrão que não respeite $\mathrm{o}$ direito a uma longevidade digna, dificilmente encontrará o ideal de sustentabilidade proposto nesse artigo.

Desse modo, corrobora Freitas (2016):

O direito à longevidade digna, assegurado mediante políticas públicas intra e intergeracionais de bem-estar físico e mental, focadas na prevenção e na precaução, com prioridade à proteção dos mais frágeis e o oferecimento de tratamento e remédios gratuitos para os carentes, assim como disciplina adequada do sistema (público e privado) de saúde (por exemplo, consulta médica em tempo razoável e o enfrentamento organizado das dependências químicas de vários matizes) (FREITAS, 2016, p. 74).

Nesse rumo, o cenário de exclusão e desrespeito ao princípio norteador da dignidade da pessoa humana precisa ser superado e conduzido a uma esfera superior de respeito, dignidade, inclusão e socialização, de modo que os direitos fundamentais e suas instituições responsáveis sejam facilmente acessados por qualquer indivíduo.

Revista do Direito [ISSN 1982-9957]. Santa Cruz do Sul, v. 2, n. 52, p. 93-111, maio/set. 2017. https://online.unisc.br/seer/index.php/direito/index 


\subsection{Direito à alimentação adequada}

O direito à adequada alimentação pressupõe uma mudança de hábito alimentar e de consumo da população, sobretudo no que diz respeito aos alimentos que são prejudiciais à saúde e que precisam ser controlados e, conforme o caso, substituídos por alimentos saudáveis, conforme assegura Freitas (2016, p. 74) "o direito à alimentação sem excesso e carências, isto é, balanceada e saudável, com amplo acesso a informação sobre os efeitos perniciosos".

Aqui, surge o tão debatido assunto dos organismos geneticamente modificados (OGM). O tema da fome no mundo é uma realidade concreta, pois a falta de uma estrutura organizada e sustentável de produção poderá levar a humanidade ao colapso alimentar.

Nessa perspectiva de escassez, surgem os defensores da utilização dos OGM, que tentam adotar esse modelo com o intento de avançar na produção alimentar, conforme apregoam Pozzetti e Fontes (2014, p. 33) "a indústria de biotecnologia investiu muito nessa técnica e tenta, através da propaganda sobre 'a grande fome que assolará o planeta', passar a informação de que os alimentos transgênicos são necessários [...]".

Ainda que existam defensores desse modelo de produção alimentar, existem também os que não o admitem em razão de seus riscos não serem, ainda, devidamente conhecidos, "os efeitos negativos, justamente pela dimensão dos riscos, atingem proporções que, se não forem adequadamente previstos e evitados, poderão acarretar consequências maiores que os benefícios" (NAVES; SILVA, 2014, p. 361).

Nesse aspecto, o direito à alimentação adequada precisa ser plenamente desenvolvido com o fito de garantir maior segurança alimentar para a população, onde os alimentos e seus riscos possam ser devidamente conhecidos pelos consumidores com o objetivo de informar e evitar demasiada contaminação alimentar.

Somente mediante a garantia de uma alimentação saudável e de boa qualidade para a população é que será possível desenvolver a dimensão jurídico-política da sustentabilidade e, em reflexo, a sustentabilidade plena.

\subsection{Direito ao meio ambiente limpo}

O direito ao pleno desenvolvimento, com vistas a proteger e preservar o meio ambiente equilibrado à sadia qualidade de vida para as presentes e futuras gerações, pressupõe um desenvolvimento direcionado à utilização de energias limpas e renováveis em detrimento dos combustíveis fósseis que degradam e poluem o planeta em larga escala, pois "a grande vantagem ambiental das fontes renováveis de energia está na mitigação de emissões de dióxido de carbono com relação às alternativas fósseis" (GOLDEMBERG; LUCON, 2012, p. 178).

Para isso, é requerida uma ação da sociedade, das organizações civis e dos governos no sentido de promover mecanismos que possam tutelar o meio ambiente equilibrado à sadia qualidade de vida intergeracional. Pressupõe ações voltadas para o combate a todo o tipo de degradação 
ambiental, da terra, da água e do solo, mediante políticas públicas adequadas e passíveis de concretização, como "inovação precípua em segurança energética, com o redesenho do plexo normativo e regulatório, apto a conferir prioridades às inovações científicas e tecnológicas de ponta, sobremodo em energias renováveis [...]" (FREITAS, 2016, p. 95).

Verifica-se que o meio ambiente está no centro das atenções voltadas ao ideal de sustentabilidade, pois é em função dele que o conceito de desenvolvimento sustentável aparece e é difundido, tendo, como objetivo, permitir o desenvolvimento das presentes gerações sem colocar em risco a qualidade de vida das gerações futuras.

Trata-se de uma justiça ambiental intergeracional, conexa ao conceito da dimensão ética da sustentabilidade, onde evidencia-se a herança ambiental que será passada da presente para a futura geração.

O meio ambiente, ecologicamente equilibrado, é condição inegociável para a existência de vida no planeta, por isso precisa ser respeitado e protegido. Não basta apenas deixar de poluir, mas buscar propagar a proteção ambiental, já que "o direito ao ambiente limpo, com vigoroso incentivo às energias renováveis, e o planejamento estatal voltado para o reequilíbrio dinâmico do sistema complexo da vida, sem inercismo inconstitucional" (FREITAS, 2016, p. 74), é uma prerrogativa incondicional.

Assim, não é possível deixar escapar à lógica, sem imediatismo, de que, somente com a propagação do direito ao meio ambiente equilibrado, é que será possível o desenvolvimento da dimensão jurídico-política da sustentabilidade.

Em consonância com as presentes gerações, o meio ambiente equilibrado e saudável é condição indispensável para a existência da vida das futuras gerações.

\subsection{Direito à educação de qualidade}

Não é demais evidenciar que o direito à educação de qualidade é ferramenta indispensável no processo de evolução humana, e tende a contribuir significativamente com o papel do desenvolvimento das dimensões da sustentabilidade que também é um processo evolutivo a ser alcançado pela humanidade.

Assim, o direito fundamental à educação de qualidade precisa ser devidamente fornecido pelo Estado, de modo a prestigiar maior acesso à participação social dos estudiosos que propõem, mediante novas ideias e soluções, uma nova reformulação do ser, do pensar e do agir no contexto social, no que tange ao plexo de sustentabilidade, tão debatido nos últimos anos. Nesse sentido, Silva e Guimarães (2014) preceituam que:

O direito à educação é a base constitutiva da formação dos cidadãos e do próprio Estado, sendo considerado pela doutrina um 'direito de síntese', pois a sua efetivação propicia e potencializa a garantia e concreção de outros direitos fundamentais, tanto de forma direta como de forma oblíqua. Por exemplo, uma pessoa que não possui educação básica adequada, dificilmente conseguirá impetrar um habeas corpus para a garantia de seus 
direito de ir e vir que, por sua vez, baseia-se no direito à democracia (SILVA; GUIMARÃES, 2014, p. 208).

Isso posto, é possível afirmar que por meio de uma educação de qualidade a humanidade terá condições de se desenvolver mediante os preceitos da sustentabilidade e suas dimensões, de modo a desenvolver raciocínio crítico referente àquilo que realmente importa do ponto de vista ambiental, ético, social e econômico.

Uma sociedade educada é realmente aquela passível de se desenvolver com mais seriedade e serenidade ambiental, onde os respeitos sejam mútuos e a conservação ambiental seja princípiosíntese estruturante de um Estado de bases democrático-participativas, como nos apresenta Freitas (2016, p. 74) "o direito à educação de qualidade, desde cedo, com destaque para o incentivo harmonioso das inteligências e da vontade (não basta, é claro, a expansão quantitativa de matrículas)".

Uma séria abordagem do direito fundamental à educação de qualidade pode gerar modificações no cenário nacional de determinado Estado ou Nação, "afinal, a cada U\$1 gasto em educação, entre U\$10 e U\$15 são gerados em crescimento econômico durante a vida profissional dos indivíduos beneficiados por esse aprendizado" (SILVA; GUIMARÃES, 2014, p. 211-212).

Desse modo, consagra-se que o direito fundamental à educação fundamental é preceito inarredável para a formação de um Estado ou de uma Nação de bases sustentáveis, pois permeia todos os conteúdos e contextos da humanidade, "demais disso, a educação também atinge diretamente o direito à segurança e, obliquamente, outros direitos como o direito à democracia, por exemplo" (SILVA; GUIMARÃES, 2014, p. 215).

Por isso, é necessário demonstrar que qualquer Estado ou Nação que esteja imbuído no desejo de se desenvolver de modo sustentável deverá, antes de tudo, despender esforços e investimentos que possam evidenciar uma melhor qualidade na educação.

\subsection{Direito à democracia}

O direito à democracia deve ser garantido de forma participativa, onde seja viabilizado o acesso de todos os cidadãos e indivíduos nos debates políticos afetos à sociedade. Esse acesso participativo deve ser efetivado por meio do uso de todos os sistemas disponíveis de informação, inclusive àquelas tecnológicas, "o direito à democracia, preferencialmente direta, com o emprego intensificado das novas tecnologias e das redes sociais, no exercício da cidadania como cerne do Estado Democrático" (FREITAS, 2016, p. 74-75).

Nesse entendimento, uma verdadeira mudança de paradigma se dará em razão do amplo acesso democrático nos debates sobre sustentabilidade e meio ambiente, em uma lógica conexa entre proteger, preservar e desenvolver.

Dessa maneira, vemos que o direito à democracia participativa é pilar de sustentação do Estado Democrático de Direito, sem o qual não há que se falar em Estado Democrático. O povo é o titular do poder absoluto no Estado Democrático de Direito, e como tal, sua voz deve ganhar força em 
torno de modificações a serem operadas no arcabouço da sociedade e do direito, conforme assevera a doutrina especializada:

Para se chegar a essa conclusão, impõe-se perceber que a democracia, atualmente, mais do que forma de Estado e de governo, é um princípio consagrado nos modernos ordenamentos constitucionais como fonte de legitimação do exercício do poder, que tem origem no povo, daí o protótipo constitucional dos Estados Democráticos, ao se declarar que todo o poder emana do povo (por exemplo, parágrafo único, do artigo $1^{\circ}$, da Constituição brasileira; artigos $3^{\circ}$ e $10^{\circ}$ da Constituição portuguesa; e artigo 20 da Lei Fundamental de Bonn, a Constituição da Alemanha) (DIAS, 2012, p. 58-59).

Portanto, é imprescindível que o direito à democracia participativa e direta seja devidamente efetivado no Estado Democrático de Direito com o fim de possibilitar o desenvolvimento da dimensão jurídico-política da sustentabilidade e o ideal democrático de participação na proteção ambiental.

Nesse mesmo contexto, Mirra (2011) assevera que: "democracia, nesse sentido, é essencialmente participação, a qual consiste na possibilidade real e concreta, aberta às pessoas em geral, de tomar parte no sistema de direção da sociedade e, em especial, no exercício e no controle do poder" (MIRRA, 2011, p. 41).

Por isso, a plena sustentabilidade pressupõe a plena democracia participativa na tomada de decisões e no exercício do poder, sob pena de não se alcançar o objetivo de desenvolvimento sustentável duradouro e intergeracional.

\subsection{Direito à informação}

O direito à informação certamente é direito fundamental no Estado Democrático de Direito e se coaduna com o próprio conceito de democracia, pois garante que o individuo devidamente informado possa exercer seu direito de participação, sendo certo que o direito fundamental à participação e o direito fundamental à informação devem caminhar de mãos dadas pelos caminhos do Estado Democrático de Direito.

Nesse sentido, Machado (2016) assegura que: "a informação serve para o processo de educação de cada pessoa e da comunidade. Mas a informação visa, também, a dar chance à pessoa informada de tomar posição ou pronunciar-se sobre a matéria informada" (MACHADO, 2016, p. 125).

Por conseqüência, é necessário que a informação seja livre, imparcial e garantida a todos os indivíduos, sem distinção de quaisquer gêneros, pois do contrário, não se está a falar em sustentabilidade, mas sim em insustentabilidade.

Tem-se, sobretudo, que a informação, no que tange à matéria de direito ambiental, precisa ser acessível em todo e qualquer momento durante o processo de licenciamento de qualquer empreendimento, pois o que está em pauta é a livre formação de opinião daquela comunidade a respeito das vantagens e desvantagens daquela obra objeto de licenciamento, pois "a informação ambiental deve ser transmitida de forma a possibilitar tempo suficiente aos informados para analisarem a matéria e poderem agir diante da Administração Pública e do Poder Judiciário" (MACHADO, 2016, p. 127). 


\subsection{Direito à razoável duração do procedimento}

Esse direito fundamental aparece como uma ferramenta tendente a eximir a chamado morosidade do Poder Judiciário que, muitas das vezes, é capaz de operar manifestas inseguranças jurídicas. Desse modo a doutrina leciona que: "entre os direitos fundamentais ligados à garantia do processo justo figura o inc. LXXVIII do art. $5^{\circ}$ da CF, no qual se asseguram, a um só tempo, (i) a razoável duração do processo, bem como (ii) o emprego dos meios que garantam a celeridade de sua tramitação" (THEODORO JÚNIOR, 2015, p. 77).

No Estado Democrático de Direito, o povo é o detentor do poder absoluto e, mediante sua insatisfação, vai defender seus direitos na esfera do Poder Judiciário, e deste espera um provimento jurisdicional capaz de por fim ao conflito.

Nessa composição, assevera a doutrina que: "o reconhecimento da duração razoável do processo e dos meios que garantem a celeridade na tramitação como direitos fundamentais da pessoa humana é de grande contribuição para o alcance dos desideratos de celeridade e eficiência" (TEIXEIRA, 2008, p. 64).

Ocorre que, para fins de sustentabilidade, a morosidade do Poder Judiciário, na entrega da tutela jurisdicional, necessita ser combatida, pois o jurisdicionado precisa de uma resposta jurídica para seu conflito, em tempo hábil a produzir seus efeitos, de modo que o bem da vida em disputa ainda esteja posto à disposição e não tenha se deteriorado em razão do tempo, ao passo que, "não sendo rápida a resposta do juízo para a pacificação do litígio, a tutela não se revela efetiva" (THEODORO JÚNIOR, 2015, p. 65).

Evidencia-se que a razoável duração do procedimento e a celeridade de sua tramitação são premissas inarredáveis no Estado Democrático de Direito por dois motivos, primeiro porque se trata de um direito fundamental de eficácia plena, instituído no bojo da Constituição da República de 1988 (CR/1988); segundo porque, para que o Estado possa alcançar a sustentabilidade, o desenvolvimento da dimensão jurídico-política se faz indispensável. Convém evidenciar o que Freitas (2016) propõe a título de razoável duração do procedimento:

O direito ao processo judicial e administrativo com desfecho tempestivo e a melhor definição cooperativa das competências, numa postura realmente dialógica e preferencialmente conciliatória, dadas as limitações do método tradicional de comando e controle (FREITAS, 2016, p. 75).

Cabe destacar, ainda que seja por meio da conciliação ou do provimento final de mérito, que o desfecho processual precisa ser realizado em tempo hábil a proteger ou entregar o bem da vida posto em disputa, sob pena de não estarem sendo cumpridos os preceitos constitucionais que regulam a matéria.

Quando se fala em tramitação do processo ambiental, a questão se coloca como ainda mais complexa, pois o meio ambiente equilibrado à sadia qualidade de vida é direito de todos, podendo ser oponível em desfavor de qualquer ação poluidora ou potencialmente poluidora. 
Nesse sentido, uma resposta jurídica adequada será aquela capaz de evitar a degradação ambiental antes mesmo que ela possa vir a causar danos irreversíveis ao meio ambiente e, para tanto, o processo precisa ser eficaz e o procedimento célere, sob pena de não resguardar o bem da vida depreciado.

\subsection{Direito à segurança}

O direito à segurança também precisa ser evidenciado para que o ideal da sustentabilidade possa se concretizar, como evidencia Freitas (2016), "o direito à segurança, com o emprego de persuasivas estratégias de ressocialização dos ímprobos e dos demais infratores, mas também de ações preventivas e ostensivas" (FREITAS, 2016, p. 75).

A segurança é premissa inarredável que deve estar na ordem do dia das autoridades, pois é por meio dela que será possível concretizar a paz social entre os indivíduos, sendo assim é necessário o desempenho de políticas públicas adequadas de combate às organizações criminosas.

Um modelo de sustentabilidade deve possibilitar, a todo cidadão e a todo indivíduo, o acesso seguro ao trabalho, ao lazer, aos locais de culto, às escolas, às praças públicas, aos locais de cultura e aos locais de competições desportivas. A sociedade tem o direito de ir e vir livremente onde desejar, sem que, para tanto, tenha que pedir permissões e concessões ao poder paralelo.

O Estado deve encontrar e evidenciar os meios necessários de garantir a segurança pública, de modo que a sociedade possa se desenvolver livremente sem os horrores da criminalização e marginalização.

Lado outro, uma sociedade sustentável é aquela livre de preceitos criminosos e do poder paralelo que insiste em perturbar os cidadãos de bem e o poder originário constituído que emana do povo.

\subsection{Direito à renda oriunda do trabalho}

O direito à renda oriunda de um trabalho digno, honesto, honroso e que transmita segurança para o trabalhador e toda a sua família, pressupõe uma conduta íntegra na relação de emprego, segundo a qual empregador e empregado possam somar forças na busca por uma melhor qualidade de vida, mediante a conduta laboral.

A sustentabilidade, nesse viés, ecoa como uma relação de emprego duradoura, sem os malefícios das expertises e das condutas desonrosas entre empregador e empregado que ao final, terminam nas esferas da justiça do trabalho.

O que se propõe é um trabalho digno de ser suportado pelo empregado, em locais descentes e livres de riscos à sua saúde, sem carga horária demasiadamente excessiva, sem o dispêndio de forças além das passíveis de serem suportadas, com salários honestos e planos de carreira acessíveis, além de direitos trabalhistas devidamente respeitados. 
Lado outro, o empregador precisa contar com a força de um trabalho honesto que respeite as políticas da empresa, que seja competente e qualificado e que não se valha de subterfúgios para fugir às atividades a serem desempenhadas.

Ainda assim, "o direito à renda oriunda do trabalho decente, com estabilidade monetária, incentivo à poupança e responsabilidade fiscal" (FREITAS, 2016, p. 75), é algo a ser alcançado por todos, sem exceção, num Estado Democrático de Direito.

Trata-se, a bem da verdade, de uma relação de emprego que deve ser fundida e consolidada nos ditames da ética e honestidade entre empregado e empregador, de modo que os dois possam ter condições de se desenvolver em conjunto rumo a uma estabilidade financeira, social e sustentável.

\subsection{Direito à boa administração pública}

Para que a sustentabilidade seja efetivamente atingida, é imperiosa a participação do Estado nas relações diárias e na regulação e distribuição da renda e dos incentivos, contudo uma boa administração pública depende do bom gerenciamento do erário público.

É imprescindível que os investimentos e incentivos governamentais se deem exatamente em função daquilo que comprovadamente importa, educação, saúde, saneamento básico, mobilidade urbana, tecnologia e ciência, com o objetivo de promover um verdadeiro avanço social do indivíduo.

Investimento com dinheiro público deve ser feito de modo consciente, sem desvios, sem individualismo, sem corrupção. Obras públicas devem ser realizadas em prol da coletividade e não para benefício de uma minoria prestigiada pelo poder econômico e político.

Nessa percepção, trata-se de uma administração pública que coloca em evidência a coletividade em detrimento do individual. A boa administração pública propõe a existência de bons administrados que tenham o condão de viabilizar o crescimento sustentável da nação objetivando o plexo da sustentabilidade.

Uma boa administração ecoa no sentido de mobilizar todas as atividades ao filtro dos princípios da prevenção e precaução, num exercício contínuo de previsibilidade de acidentes que possam vir a ser catastróficos do ponto de vista ambiental. Desse modo, preceitua a doutrina:

De fato, se é certo que a nossa Carta está, em consonância com os princípios da Carta das Nações Unidas e com os Objetivos do Desenvolvimento Sustentável, cumpre, na vida real, exigir, por exemplo, que os gastos, renúncias fiscais e investimentos públicos passem a respeitar a eficácia direta do desenvolvimento durável, de modo a serem efetivamente sopesados os custos e benefícios, diretos e indiretos (externalidades), sociais, econômicas e ambientais (FREITAS, 2016, p. 3435).

No enfoque de uma boa administração pública evidencia-se que os administradores sejam capazes de utilizar o erário público de forma consciente, objetiva e honesta, de modo a priorizar a coletividade em prejuízo de seus próprios interesses.

Consoante ao mencionado anteriormente, aponta Freitas (2016) que: "o direito à boa administração pública, com a indeclinável regulação das atividades essenciais e socialmente 
relevantes, à vista de que o Estado Sustentável guarda comprovada relação com o bem-estar" (FREITAS, 2016, p. 75-76). Por isso, a boa administração pública precisa ser devidamente efetivada, para ser capaz de produzir bem-estar em favor das presentes e futuras gerações.

A Administração Pública tem o dever para com a sociedade de efetivar políticas públicas que evidenciem o bem-estar social de modo a destinar investimentos que sejam capazes de propagar o lazer, o trabalho, a mobilidade urbana, o saneamento básico e a saúde.

\subsection{Direito à moradia digna}

O direito a uma moradia digna pressupõe um desenvolvimento que leve em consideração a segurança habitacional e a efetiva regulação do direito de propriedade. Trata-se de direito social por excelência, mas também, encontra espaço na dimensão jurídico-política da sustentabilidade, por fazer parte de um conjunto de conceitos que precisam ser devidamente consubstanciados pelo Poder Público no objetivo mútuo de desenvolvimento pautado na sustentabilidade.

Ante o exposto, é certo que o direito à moradia digna e segura é questão indispensável à existência da vida humana, pois a dignidade da pessoa humana vislumbra que o homem deve habitar casas e apartamentos e não calçadas, e muito menos debaixo de pontes e viadutos.

As pessoas devem residir em locais seguros, que comportem a vida de modo concreto e duradouro, casas construídas em áreas de riscos devem ser imediatamente interditadas, dado que é insustentável que as mudanças das estações possam levar tantas pessoas a óbito. Nesse enquadramento Freitas (2016) propõe a "[...] remoção das pessoas das áreas de risco, fiscalização periódica que evite o inaceitável desabamento de prédios, cumprimento da multifuncionalidade (social, ambiental e econômica) das propriedades públicas e privadas [...]" (FREITAS, 2016, p. 76).

É importante que o acesso à moradia digna seja possibilitado pelo governo com a finalidade de promover o assentamento dos menos favorecidos e nesse viés, "[...] crédito sem bolha especulativa, disseminação do conceito de casa saudável e o emprego de tecnologias 'verdes' para a construção e reconstrução, com baixo dispêndio energético" (FREITAS, 2016, p. 76).

Considerando o que até aqui foi exposto, evidencia-se que a dimensão jurídico-política da sustentabilidade, assim como a dimensão social, econômica, ética e ambiental, precisam ser devidamente contempladas e implementadas no Estado Democrático de Direito com o fito específico de possibilitar o pleno desenvolvimento, pautado na sustentabilidade que revela a possibilidade da vida gozada com bem-estar para as presentes e futuras gerações.

As dimensões da sustentabilidade, que ora são abordadas nesse artigo, precisam ser tratadas em específica sincronia de desenvolvimento, pois o atraso de qualquer uma delas não ensejará a sustentabilidade.

Tendo como base o tratado até aqui, o próximo capítulo tratará de tema específico que está contido no seio da dimensão jurídico-política da sustentabilidade, qual seja, o direito fundamental à razoável duração do procedimento, que vem sendo sistematicamente negligenciado pelo Poder Judiciário, sendo certo que seu avanço é condição inarredável para se alcançar a sustentabilidade. 


\section{O DIREITO FUNDAMENTAL À RAZOÁVEL DURAÇÃO DO PROCEDIMENTO SOB A ÓTICA DA DIMENSÃO JURÍDICO-POLÍTICA DA SUSTENTABILIDADE}

Demonstrado até o momento que o desenvolvimento sustentável é uma premissa inafastável que precisa ser difundida e implementada com vistas a estabelecer condições de bem-estar para as presentes e futuras gerações, o conceito de sustentabilidade surge como princípio-síntese capaz de possibilitar maior justiça intrageracional e intergeracional.

No entanto, para que a verdadeira sustentabilidade que importa seja devidamente atingida, é inegociável que seja desenvolvida nas cinco dimensões trabalhadas nesse artigo, quais sejam: dimensão social; dimensão econômica; dimensão ética, dimensão ambiental e dimensão jurídicopolítica.

Essas cinco dimensões são premissas fundantes do ideal de sustentabilidade, de modo que devem ser desenvolvidas e implementadas em conjunto, sem o atraso de nenhuma delas, pois nesse caso estar-se-á a falar em insustentabilidade e não em sustentabilidade, como apresentado por Freitas: "tais dimensões (ética, jurídico-política, ambiental, social e econômica) se entrelaçam e se constituem mutuamente, numa dialética da sustentabilidade, que não pode, sob pena de irremediável prejuízo, ser rompido" (FREITAS, 2016, p. 77).

Ocorre que, o direito fundamental à razoável duração do procedimento que está estabelecido no art. $5^{\circ}$, inciso LXXVIII, da CR/1988, aparece como um mecanismo viável a corroborar com o avanço da dimensão jurídico-política da sustentabilidade. Inegável que toda sociedade de direito, que busque no Poder Judiciário a resolução de seus conflitos merece uma resposta adequada e em tempo hábil a produzir seus efeitos.

Nesse contexto, antes que se fale em sustentabilidade, é imprescindível que o evidente problema da morosidade do Poder Judiciário seja devidamente enfrentado pelo Poder Público e pela administração da justiça, pois sem a razoável duração do procedimento não há a efetividade da dimensão jurídico-política e, sem essa dimensão, não há sustentabilidade, portanto, a discussão se faz necessária.

Afigura-se que o direito fundamental à razoável duração do procedimento está insculpido no art. $5^{\circ}$, inciso LXXVIII, da CR/1988 nos seguintes termos: "a todos, no âmbito judicial e administrativo, são assegurados a razoável duração do processo e os meios que garantam a celeridade de sua tramitação" (BRASIL, 1988).

Nesse mesmo sentido, deve ser evidenciada norma que compõe o Capítulo I - Das Normas Fundamentais do Processo Civil. No art. $4^{\circ}$ do Novo Código de Processo Civil (NCPC): "as partes têm o direito de obter em prazo razoável a solução integral do mérito, incluída a atividade satisfativa" (BRASIL, 2015).

Comprova-se, portanto, o direito à razoável duração do procedimento, além de constar como norma de direito fundamental assegurada pela CR/1998, consta também nas normas fundamentais do NCPC, dada a sua importância, que merece ser propagada e difundida.

O princípio da efetividade do processo atua como norteador do Estado Democrático de Direito que visa implementar o processo justo, ao passo que o processo lento e moroso não é justo, por 
gerar desigualdades entre os jurisdicionados. Dias (2012) aponta que é obrigação direta do Estado garantir a razoável duração do procedimento:

Logo, o direito fundamental do povo de acesso à jurisdição também abrange o direito de obter do Estado um pronunciamento decisório em prazo razoável. Se descumprida pelo Estado esta recomendação constitucional, a função jurisdicional do estado se qualifica como inacessível ao povo, por não apresentar solução decisória em lapso temporal útil, no processo que a provocou, em aberto desrespeito ao texto da Constituição (art. $5^{\circ}$, inciso LXXVIII), sujeitando o mesmo Estado à obrigação de reparar os danos causados ao jurisdicionado, se o prejudicado suscitar sua responsabilidade civil em procedimento próprio (DIAS, 2012, p. 162).

O direito à razoável duração do procedimento mostra, a um só tempo, o direito a uma razoabilidade de prazo de duração do processo e uma maior celeridade na marcha procedimental, sem dilações indevidas e estrita obediência às regras procedimentais propostas pela lei. Observa-se que uma razoável duração de uma demanda está voltada para um conjunto de atos que, se realizados de maneira uniforme, irão permitir que a tutela jurisdicional seja entregue em tempo hábil a produzir seus efeitos.

Sabe-se que um processo justo depende diretamente da ética entre as partes, de modo que demandante e demandado devem atuar com a lealdade processual que a lei exige, evitando dilações imprestáveis e procrastinações injustificáveis, mais do que isso, é imprescindível que as partes proponham uma célere tramitação procedimental com ações positivas tendentes a simplificar ritos e comandos permitidos pela lei processual.

Por outro lado, observa-se que o Estado tem a obrigação de entregar a tutela jurisdicional em tempo hábil, e isso implica uma série de esforços a serem somados em favor da célere tramitação procedimental com vistas à adequação do Poder Judiciário a essa realidade. Dias (2012) observa que: "é a lentidão, a morosidade da atividade jurisdicional, quase sempre imputável à negligência do Estado, que leva a se decidir pela inobservância do prazo razoável de duração dos processos" (DIAS, 2012, p. 171).

É indispensável que a administração da justiça trabalhe em favor de extinguir as etapas mortas do processo, que são aquelas em que os autos processuais ficam engavetados na secretaria do juízo sem nenhuma destinação específica. "O que não se pode tolerar é a procrastinação injustificável decorrente da pouca ou total ineficiência dos serviços judiciários, de modo que a garantia de duração razoável se traduz na marcha do processo sem delongas inexplicáveis e intoleráveis" (THEODORO JÚNIOR, 2015, p. 65-66).

É bem verdade que a garantia da duração razoável do processo deve ser assegurada pelo Poder Judiciário com o intento de consubstanciar o processo justo, sem, contudo, sacrificar as garantias processuais do contraditório e da ampla defesa, por serem garantias que jamais podem ser superadas na esfera processual, sendo certo que o princípio da duração razoável visa a combater dilações indevidas e impróprias e, sobretudo o tempo morto nas secretarias e gabinetes.

Não se trata de uma sumarização do processo e do procedimento a todo custo, trata-se de tempo hábil a produzir efeitos, conforme ensina Dias (2012): 
Assinala-se que a exigência constitucional de se obter a prestação da atividade jurisdicional em tempo útil ou prazo razoável, o que significa adequação temporal da jurisdição, mediante processo sem dilações indevidas, não permite o Estado impingir ao povo a aceleração dos procedimentos pela diminuição das demais garantias processuais constitucionais (DIAS, 2012, p. 163).

A morosidade do Poder Judiciário na entrega da tutela jurisdicional é uma realidade que precisa ser combatida por meio de um esforço conjunto entre as partes: Poder Judiciário e Estado, de modo a efetivar os ditames do direito fundamental à razoável duração do procedimento, sem, contudo, ferir os princípios do contraditório e da ampla defesa.

É de fundamental importância o combate à morosidade do Poder Judiciário no que tange a entrega da tutela jurisdicional, pois o que está sendo mitigado com essa morosidade é o próprio acesso à jurisdição e o acesso ao processo justo, o que no Estado Democrático de Direito é inconcebível.

Essa morosidade procedimental aponta para um sentimento negativo em relação ao jurisdicionado, que se vendo em situação de inconformismo, deixa de acreditar no Poder Judiciário como meio hábil de resolver seus conflitos, conforme aponta Teixeira (2008):

A morosidade do Poder Judiciário na entrega da tutela jurisdicional é uma realidade que precisa ser combatida por meio de um esforço conjunto entre as partes: Poder Judiciário e Estado, de modo a efetivar os ditames do direito fundamental à razoável duração do procedimento, sem, contudo, ferir os princípios do contraditório e da ampla defesa.

É de fundamental importância o combate à morosidade do Poder Judiciário no que tange a entrega da tutela jurisdicional, pois o que está sendo mitigado com essa morosidade é o próprio acesso à jurisdição e o acesso ao processo justo, o que no Estado Democrático de Direito é inconcebível. Essa morosidade procedimental aponta para um sentimento negativo em relação ao jurisdicionado, que se vendo em situação de inconformismo, deixa de acreditar no Poder Judiciário como meio hábil de resolver seus conflitos, conforme aponta Teixeira (2008):

Revela-se que, no Estado Democrático de Direito o fenômeno da morosidade na entrega da tutela jurisdicional precisa ser combatida por meio de políticas adequadas, tendentes a respeitar e efetivar o direito fundamental do cidadão à razoável duração do procedimento e à celeridade de sua tramitação, de modo a consubstanciar o processo justo e o acesso à jurisdição.

Um processo jurisdicional lento, moroso, propagador de angústia e de ilegalidades temporais, que não se amolda ao Estado Democrático de Direito, é um fomentador de mal-estar para a sociedade e, caminha no sentido oposto ao conceito de sustentabilidade, que visa a implantar o bemestar em favor das presentes e futuras gerações.

Nesse passo, observa-se que a morosidade do Poder Judiciário na entrega da tutela jurisdicional é insustentável, pois não efetiva, em sua integralidade, a dimensão jurídico-política da sustentabilidade, que propõe um processo justo, com duração razoável e com desfecho tempestivo.

Portanto, verifica-se que medidas conceituais e estruturais precisam ser aplicadas com o objetivo de revisitar antigas compreensões processuais sobre razoável duração do procedimento, na busca por um ideal democrático e sustentável de desenvolvimento pautado na sustentabilidade e propagador do bem-estar, de modo a cumprir o objetivo $\mathrm{n}^{\circ} 16$ dos ODS. 


\section{CONSIDERAÇÕES FINAIS}

Ao final desse estudo é possível considerar que o sistema capitalista vigente desde meados dos anos de 1970, precisa ser superado e permutado para um modelo de desenvolvimento pautado na sustentabilidade, tendente a conciliar a vida e o bem-estar das presentes e futuras gerações, com o efetivo desdobramento do princípio da solidariedade intra e intergeracional.

Desse modo, observou-se que a sustentabilidade possui um conceito e um caráter multidimensional, e propõe o avanço das dimensões, social, econômica, ética, ambiental e jurídicopolítica, onde elas possam ser efetivadas mutuamente, de forma a alcançar o plexo da sustentabilidade. Considera-se que as dimensões da sustentabilidade são entrelaçadas e que seu desenvolvimento deve ocorrer de modo conjugado, onde nenhuma delas possa ser esquecida ou postergada, sob pena de insustentabilidade.

Nesse sentido, observou-se que a dimensão jurídico-política da sustentabilidade não vem sendo efetivada no Estado Democrático de Direito com sucesso, apesar dessa dimensão ter como meta produzir o bem-estar mediante o pleno desenvolvimento dos direitos fundamentais.

A razoável duração do procedimento é um direito fundamental por excelência e vem, sistematicamente, sofrendo limitações no Poder Judiciário que, de forma impressionante, não consegue entregar a tutela jurisdicional em tempo hábil a produzir seus efeitos, ficando evidente que a dimensão jurídico-política da sustentabilidade está sendo constantemente prejudicada.

Constatou-se, pelos estudos feitos e aqui demonstrados, que a morosidade do Poder Judiciário na entrega da tutela jurisdicional gera sérios prejuízos ao jurisdicionado, ao passo que ele passa a ser privado de seu bem da vida, ou do direito material que está sendo posto em litígio.

Observou-se ainda que, no Estado Democrático de Direito, é inaceitável permitir e coadunar com a morosidade do Poder Judiciário na entrega da tutela jurisdicional, pois, além de evidenciar a impotência do Estado no que tange à resolução de conflitos e à evidente falta de aplicação de um processo justo, mitiga o próprio acesso à jurisdição.

Assim, é necessário um esforço conjunto entre as partes, o Poder Judiciário e o Estado, no objetivo de diminuir o tempo de duração das demandas judiciais e garantir a celeridade de tramitação, mediante a efetivação de uma conduta leal entre os envolvidos, a eliminação de etapas mortas no curso do procedimento e a completa reorganização das estruturas do Poder Judiciário.

A morosidade na entrega da tutela jurisdicional é fenômeno que pode levar à insustentabilidade do Estado e, por isso, precisa ser combatida por meio de ações positivas, no sentindo de notabilizar possibilidades de uma tramitação processual célere que respeite, contudo, os princípios do contraditório e da ampla defesa.

O presente estudo não defende a mitigação do devido processo legal e muito menos a desvalorização dos princípios do contraditório e da ampla defesa. Pelo contrário, essa pesquisa tenta deixar claro que a lentidão do Poder Judiciário na resolução de conflitos gera flagrantes inseguranças jurídicas e injustiças intra e intergeracionais, vez que o jurisdicionado passa a não mais acreditar no modelo jurisdicional monopolizado pelo Estado. 
Tem-se que a morosidade do Poder Judiciário precisa ser devidamente enfrentada e combatida pelos poderes constituídos, visto que o Estado Democrático de Direito pressupõe que o poder soberano emane do povo mediante o livre exercício do acesso à jurisdição para soluções de conflitos.

Nessa linha, se não combatido o fenômeno da morosidade do Poder Judiciário na entrega da tutela jurisdicional, de modo a efetivar o princípio fundamental da razoável duração do procedimento, não será possível evidenciar o desenvolvimento do plexo da sustentabilidade, por falta de efetivação de sua dimensão jurídico-política.

Assim, é necessário compreender que o desenvolvimento pautado na sustentabilidade, somente se dará mediante o avanço conjunto de todas as dimensões: social, econômica, ética, ambiental e jurídico-política, pois o atraso de qualquer uma delas consistirá em flagrante insustentabilidade.

Concluindo, é possível considerar que a dimensão jurídico-política da sustentabilidade precisa ser desenvolvida em sua integralidade, de modo a consubstanciar a efetivação do direito à longevidade digna, do direito à alimentação adequada, do direito ao ambiente limpo, do direito à educação de qualidade, do direito à democracia, do direito à informação, do direito à razoável duração do procedimento, do direito à segurança, do direito à renda oriunda do trabalho, do direito à boa administração pública e do direito à moradia digna, pois do contrário estar-se-á a evidenciar a completa insustentabilidade.

O Estado, para se tornar sustentável, segundo o modelo de sustentabilidade duradoura que permita a continuidade da vida para as presentes e futuras gerações, precisa, antes de tudo, combater o fenômeno da morosidade do Poder Judiciário, com vistas a produzir segurança jurídica, bem estar social e a efetividade da dimensão jurídico-política da sustentabilidade.

\section{REFERÊNCIAS}

BRASIL. Código de Processo Civil (2015). Código de Processo Civil Brasileiro. Diário Oficial, Brasília, 18 mar. 2015.

BRASIL. Constituição (1988). Constituição da República Federativa do Brasil. Diário Oficial, Brasília, 05 out. 1988.

BIZAWU, Kiwonghi; GOMES, Magno Federici. Oil exploitation at Virunga park as a threat to the environment and to endangered animal species. Veredas do Direito, Belo Horizonte, v. 13, n. 27, p. 11-29, set./dez. $2016 . \quad$ Disponível em: <http://www.domhelder.edu.br/revista/index.php/veredas/article/view/897>. Acesso em: 14 jan. 2017.

CRUZ, Paulo Márcio; GLASENAPP, Maikon Cristiano. Sustentabilidade: um novo paradigma para o direito. luris Tantum, Lomas Anáhuac, $\mathrm{n}^{\circ}$ 25, p. 367-387, dez. 2014. Disponível em: <http://app.vlex.com/\#WW/vid/589184090/graphical version>. Acesso em: 09 jul. 2016.

DIAS, Ronaldo Brêtas de Carvalho. Processo constitucional e Estado democrático de direito. 2. ed. Belo Horizonte: Del Rey, 2012.

FREITAS, Juarez. Sustentabilidade: direito ao futuro. 3. ed. Belo Horizonte: Fórum, 2016.

FROEHLICH, Cristiane. Sustentabilidade: dimensões e métodos de mensuração de resultados. Revista de Gestão do Unilasalle, Canoas, v. 3, n० 2, p. 151-168, set. 2014. Disponível em: <http://www.revistas.unilasalle.edu.br/index.php/desenvolve/article/view/1316/1182>. Acesso em: 09 jul. 2016. 
GOLDEMBERG, José; LUCON, Oswaldo. Energia, meio ambiente e desenvolvimento. 3. ed. São Paulo: Universidade de São Paulo, 2012.

MACHADO, Paulo Affonso Leme. Direito ambiental brasileiro. 24. ed. São Paulo: Malheiros, 2016.

MAFRA, Juliete Ruana. O paradigma da sustentabilidade no ordenamento jurídico brasileiro: um direito fundamental material. Revista Eletrônica Direito e Política, Itajaí, v. 10, n 1, p. 547-566, jan. 2015. Disponível em: <http://siaiap32.univali.br/seer/index.php/rdp/article/view/7182/4080>. Acesso em: 09 jul. 2016.

MIRRA, Álvaro Luiz Valery. Participação, processo civil e defesa do meio ambiente. São Paulo: Letras Jurídicas, 2011.

NAVES, Bruno Torquato de Oliveira; SILVA, Marcela Vitoriano e. Organismos geneticamente modificados sob a perspectiva da tutela das gerações futuras. Veredas do Direito, Belo Horizonte, v. 11, $\mathrm{n}^{\circ} \quad 22, \quad$ p. 355-380, jul./dez. 2014. Disponível em: $<$ http://www.domhelder.edu.br/revista/index.php/veredas/article/view/473/428>. Acesso em: 09 maio 2016.

ORGANIZAÇÃO DAS NAÇÕES UNIDAS. Os objetivos de desenvolvimento sustentável: dos ODM aos ODS. Programa das Nações Unidas para o desenvolvimento (PNUD). Disponível em: <http://www.pnud.org.br/ODS.aspx>. Acesso em: 09 jul. 2016.

POZZETTI, Valmir Cesar; FONTES, Gustavo Rosa. Rastreabilidade de organismos geneticamente modificados (OGMs): instrumento de proteção ao consumidor e ao meio ambiente. Veredas do Direito, Belo Horizonte, v. 11, $\mathrm{n}^{\circ}$ 21, p. 31-52, jan./jun. 2014. Disponível em: $<$ http://www.domhelder.edu.br/revista/index.php/veredas/article/view/420/396>. Acesso em: 09 jul. 2016.

SACHS, Ignacy. Caminhos para o desenvolvimento sustentável. Rio de Janeiro: Garamond, 2009.

SILVA, José Afonso da. Curso de direito constitucional positivo. 37. ed. São Paulo: Malheiros, 2014.

SILVA, Lucas do Monte; GUIMARÃES, Patrícia Borba Vilar. A efetivação de direitos fundamentais: a relação entre o desenvolvimento e o plexo constitucional. Veredas do Direito, Belo Horizonte, v. 11, no 22, $\quad$ p. 199-223, jul./dez. 2014. Disponível em: $<$ http://www.domhelder.edu.br/revista/index.php/veredas/article/view/449/436>. Acesso em: 09 jul. 2016.

TEIXEIRA, Antônio Edílio Magalhães. Processo ambiental: uma proposta de razoabilidade na duração do processo. Curitiba: Juruá, 2008.

THEODORO JÚNIOR, Humberto. Curso de direito processual civil: teoria geral do direito processual civil, processo de conhecimento e procedimento comum. 56. ed. Rio de Janeiro: Forense, 2015. v. 1.

\section{COMO CITAR ESSE DOCUMENTO:}

GOMES, Magno Federici; FERREIRA, Leandro José. A dimensão jurídico-política da sustentabilidade e o direito fundamental à razoável duração do procedimento. Revista do Direito, Santa Cruz do Sul, v. 2, n. 52, out. 2017. ISSN 1982-9957. Disponível em: <https://online.unisc.br/seer/index.php/direito/article/view/8864>. Acesso em: doi:http://dx.doi.org/10.17058/rdunisc.v2i52.8864. 